\begin{tabular}{|c|l|}
\hline Title & Design and synthesis of the stabilized anal ogs of belactosin A with the unnatural cis cyclopropane structure \\
\hline Author(s) & Kawamura, Shuhei; Unno, Yuka; A sai, A kira; A risawa, Mitsuhiro; Shuto, Satoshi \\
\hline Citation & $\begin{array}{l}\text { Organic \& biomolecular chemistry, 11/38), 6615-6622 } \\
\text { https://doi.org/10.1039/c30b41338a }\end{array}$ \\
\hline Issue Date & 2013_10-14 \\
\hline Doc URL & http://hdl.handle.net/2115/56729 \\
\hline Type & article (author version) \\
\hline File Information & WoS_63009_Shuto.pdf \\
\hline
\end{tabular}

Instructions for use 


\section{Design and Synthesis of the Stabilized Analogs of Belactosin A with the Unnatural cis-Cyclopropane Structure}

Shuhei Kawamura, ${ }^{a}$ Yuka Unno, ${ }^{c}$ Akira Asai, ${ }^{c}$ Mitsuhiro Arisawa, ${ }^{a}$ Satoshi Shuto ${ }^{*}, a, b$.

${ }^{\mathrm{a}}$ Faculty of Pharmaceutical Sciences and ${ }^{\mathrm{b}}$ Center for Research and Education on Drug Discovery, Hokkaido University, Kita-12, Nishi-6, Kita-ku, Sapporo 060-0812, Japan

${ }^{\mathrm{c}}$ Graduate School of Pharmaceutical Sciences, University of Shizuoka, Yada, Shizuoka 422-8526, Japan

Running Title: Stabilization of the cis-Belactosin A Analogs

Corresponding Author: Satoshi Shuto

Phone \& Fax: +81-11-706-3769.

E-mail: shu@pharm.hokudai.ac.jp 


\section{Abstract}

The belactosin A analog 2a, having the unnatural cis-cyclopropane structure instead of the trans-cyclopropane structure in belactosin A, is a much more potent proteasome inhibitor than belactosin A. However, its cell growth inhibitory effect is rather lower than that expected from its remarkable proteasome inhibitory effect, probably due to its instability under cellular conditions. We hypothesized that the instability of $\mathbf{2 a}$ was due to its chemical and enzymatic hydrolysis of the strained $\beta$-lactone moiety. Thus, to increase the stability of 2a by chemical modification, its analogs with a sterically more hindered $\beta$-lactone moiety and/or cyclopropylic strain-based conformational restriction were designed and synthesized, resulting in the identification of a stabilized analog $\mathbf{6 a}$ as a proteasome inhibitor with cell growth inhibitory effects. Our findings suggest that the chemical and biological stability of $\mathbf{2 a}$ is significantly affected by the steric hindrance around its $\beta$-lactone carbonyl moiety and the conformational flexibility of the molecule.

\section{Introduction}

The chemical and biological stability of small molecules depend on their chemical structures, and therefore it can be regulated by structural modifications. ${ }^{1}$ In the drug discovery process, compounds with insufficient stability often degrade rapidly in vivo and sometimes bind covalently to off-target molecules, resulting in the absence of the desired pharmacological effect, and even worse, producing an undesired toxic side-effect. ${ }^{2}$ The chemical and biological instability of compounds can be improved by changing the steric and/or electrostatic properties of the labile moiety. Furthermore, when the compound is unstable in vivo due to enzymatic degradation, it can be stabilized by changing of such structural features as molecular size, electrostatic property, hydrophobicity, and conformation to reduce the affinity for the degrading enzyme.

The ubiquitin-proteasome system is the major degradation pathway of intracellular proteins, ${ }^{3}$ which are involved in many physiologically important cellular processes, such as signal transduction, ${ }^{4}$ cell cycle progression, ${ }^{5}$ and unfolded protein response (UPR). ${ }^{6}$ Because inhibition of the proteasome causes cell cycle arrest to induce apoptosis, proteasome is an attractive target for the development of anti-cancer drugs. ${ }^{7}$ For example, a proteasome inhibitor bortezomib is clinically effective for the treatment of the multiple myeloma ${ }^{8}$ and mantle cell lymphoma. ${ }^{9}$

Belactosin A is a proteasome inhibitor isolated from the Streptomyces sp. by Asai, ${ }^{10}$ which inhibits proteasome covalently by acylating the active site Thr residue via ring-cleavage of its strained $\beta$-lactone moiety. ${ }^{11}$ Because the binding site of belactosin derivatives differs from that of other proteasome inhibitors, ${ }^{11-12}$ belactosin $\mathrm{A}$ is an attractive potential lead for the development of novel proteasome inhibitors. In recent years, we have investigated the three-dimensional structure activity relationship (SAR) study of belactosin A and identified the unnatural cis-cyclopropane isomer $\mathbf{1}$ as a more potent proteasome inhibitor than belactosin A having the trans-cyclopropane structure. ${ }^{13}$ Furthermore, we investigated the SAR of $\mathbf{1}$ to result in identification of the optimized inhibitor 2a, which appeared to be as potent as the clinical drug bortezomib (Figure 2) ${ }^{14}$ Despite its remarkable proteasome inhibitory effect, however, its inhibitory effect on cell growth is not so strong, compared with other potent inhibitors such as bortezomib $^{15}$ or carfilzomib, ${ }^{16}$ as summarized in Table 1 . In our previous study, we investigated the stability of $\mathbf{2} \mathbf{b}$, instead of 2a due to its poor solubility in aqueous medium, and demonstrated that $\mathbf{2} \mathbf{b}$ is gradually degraded in aqueous medium, while its half-life $\left(\mathrm{t}_{1 / 2}=10 \mathrm{~h} \text { in } \mathrm{pH} 7.4 \text { buffer }\right)^{14 \mathrm{~b}}$ is longer than that of other $\beta$-lactone-type proteasome inhibitors (omuralide, $13 \mathrm{~min}$; salinosporamide A, $56 \mathrm{~min}$ ). ${ }^{17}$ Furthermore, it was found that $\mathbf{2 b}$ is significantly unstable under biological conditions ( $\mathrm{t}_{1 / 2}=2.3 \mathrm{~min}$ in serum), which might be correlated with the relatively weak cell growth 
inhibitory effect of $\mathbf{2 a}$, because $\mathbf{2 a}$ can be as unstable as $\mathbf{2} \mathbf{b}$. Thus, we planned to develop stabilized derivatives of $\mathbf{2 a}$. Here we describe the design, synthesis, biological activities, and chemical and biological stability of the newly designed compounds.

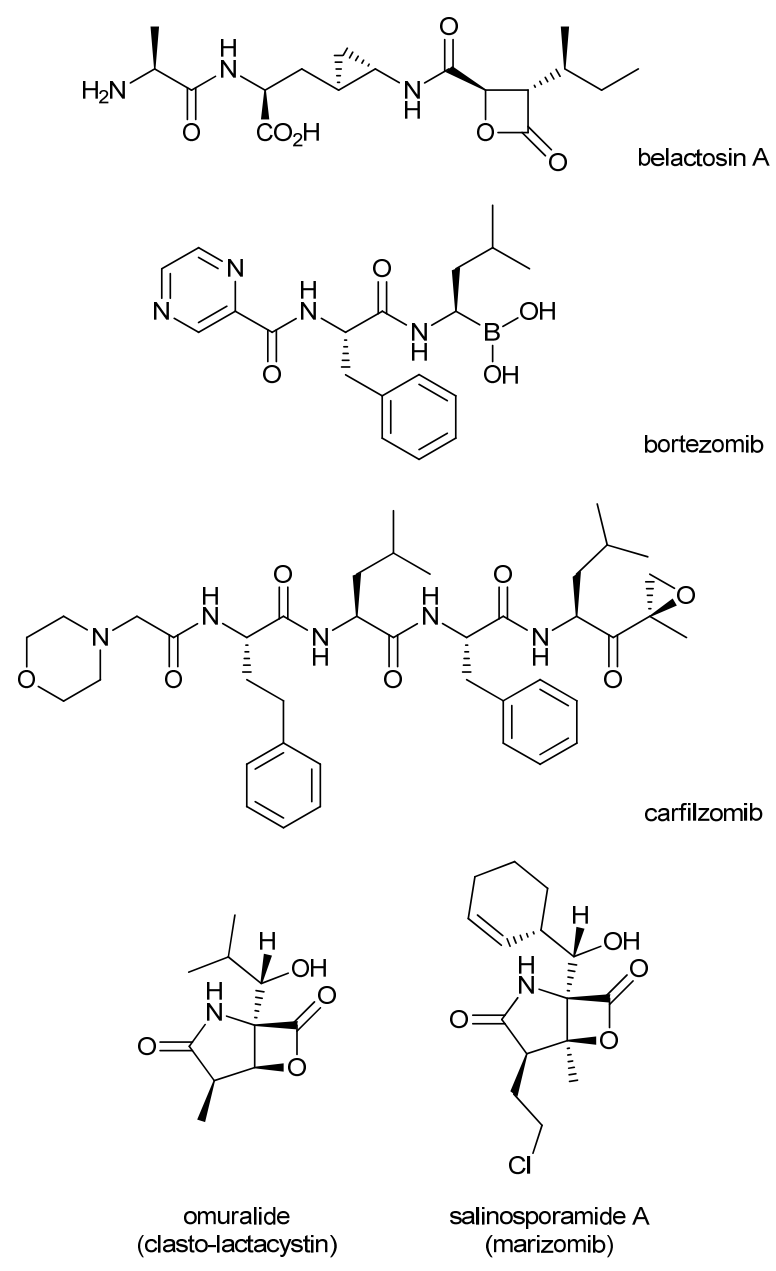

Figure 1. Known proteasome inhibitors 

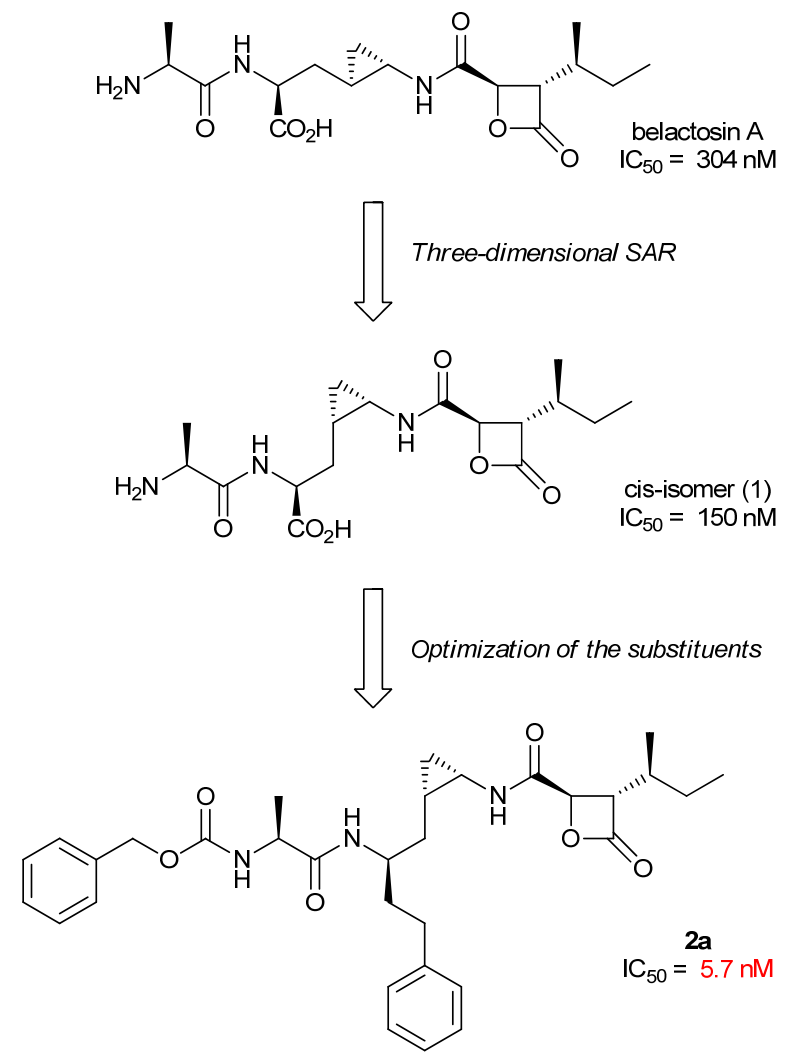

Figure 2. Previous SAR studies of belactosin A performed by our laboratory.

Table 1. Inhibitory effect of 2a, bortezomib and carfilzomib on proteasome chymotrypsin-like (CT-L) activity and HCT116 cell growth

\begin{tabular}{|c|c|c|c|}
\hline \multirow{2}{*}{ compound } & \multicolumn{2}{|c|}{$\mathrm{IC}_{50}[\mathrm{nM}]$} & \multirow{2}{*}{$\begin{array}{c}\mathrm{IC}_{50} \text { ratio } \\
\text { (cell growth/CT-L activity) }\end{array}$} \\
\hline & proteasome (CT-L activity) & cell growth (HCT116) & \\
\hline $2 \mathbf{a}$ & 5.7 & 1820 & 319 \\
\hline bortezomib & 4.5 & 5.0 & 1.1 \\
\hline carfilzomib & 6.3 & 8.5 & 1.3 \\
\hline
\end{tabular}

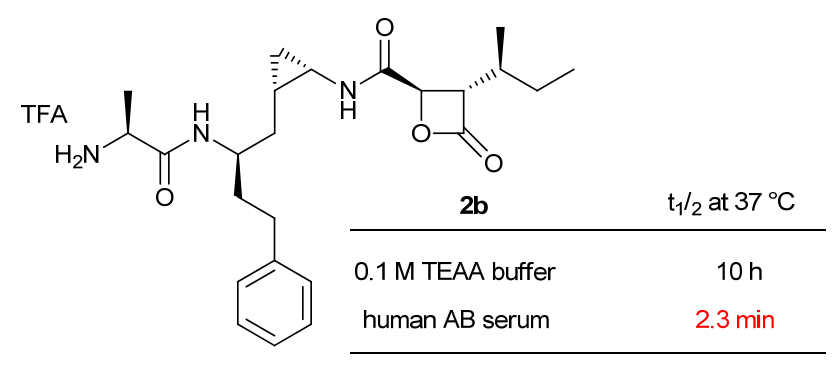

Figure 3. Stability of $\mathbf{2 b}$ in $0.1 \mathrm{M}$ TEAA buffer $(\mathrm{pH} 7.4)$ and human $\mathrm{AB}$ serum at $37^{\circ} \mathrm{C}$

\section{Results and Discussion}

Design of compounds. The reactivity of the carbonyl group with nucleophiles is affected by the steric hindrance 
around its carbon atom, ${ }^{18}$ and we therefore designed compounds 3a-5a with various substituents at the $\alpha$-carbon of the $\beta$-lactone carbonyl group of 2a (Figure 4-a) to change the bulkiness at the position. The order of the steric hindrance around the $\beta$-lactone carbonyl group is thought to be $\mathbf{3 a}<\mathbf{2} \mathbf{a}<\mathbf{4 a}<\mathbf{5 a}$, as depicted in Figure 4-a.

On the other hand, because enzyme recognition can be influenced by the three-dimensional structure of the substrate, conformational restriction of $\mathbf{2 a}$ and its analogs might result in lowering the affinity for the degrading enzyme, and we therefore designed $\mathbf{6 a}$ as a conformationally restricted analog. The cis-oriented adjacent substituents on the cyclopropane ring are fixed in the eclipsed orientation, and accordingly, they exert significant mutual steric repulsion, which we previously termed "cyclopropylic strain”. ${ }^{19}$ Due to this characteristic structural feature, conformation of the substituents (Figure 5-a) on a cyclopropane ring can be restricted, and therefore, in compound 5a, conformer A (anti, the cyclopropane ring “down”/the side chain "up”) and B (syn, the cyclopropane ring “down”/the side chain “down”) would be preferable (Figure 5-b). Previously, we demonstrated that the bioactive conformation of the cis-cyclopropane belactosin derivatives seems to be syn. ${ }^{20}$ Therefore, we designed conformationally restricted analog 6a (Figure 4-b), whose conformation is restricted in the syn-form due to the significant steric repulsion between the introduced 1 'R-methyl group and the cis-oriented amide group in its anti-form (Figure 5-b). Notably, this cyclopropylic strain-based conformational restriction can be achieved by the minimal structural change, i.e., only the introduction of a methyl group, allowing us to more rigorously investigate the relationship between the conformation and the stability.

The compounds 3a-6a were thought to be poorly soluble in aqueous medium, therefore we also planned to synthesize compounds 3b-6b, which are analogs of 3a-6a without the $N$-terminal Cbz group, to evaluate their stability under aqueous conditions instead of 3a-6a.

a<smiles>[R]N[C@H](C)C(=O)N[C@H](CCc1ccccc1)C[C@H]1C[C@@H]1NC(=O)[C@@H]1OC(=O)[C@H]1CC(C)C</smiles>

2

small

steric hindrance

large

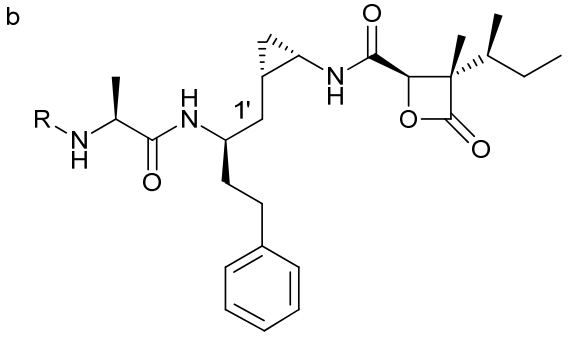

5
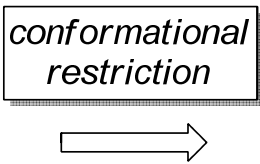

$\square$
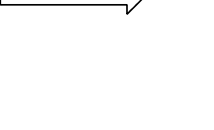

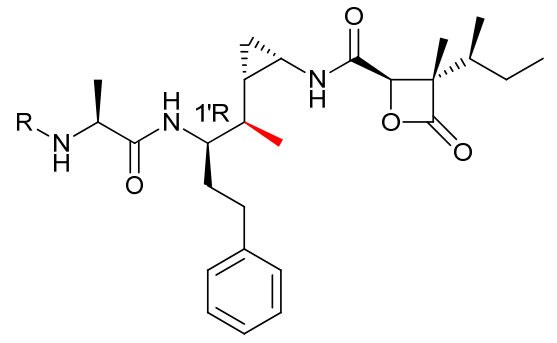

Figure 4. Structure of newly designed compounds 3-6 and their parent compound 2. (a) Relative steric hindrance 
around the $\beta$-lactone carbonyl group is also shown. (b) The structure of conformationally restricted analog 6 .
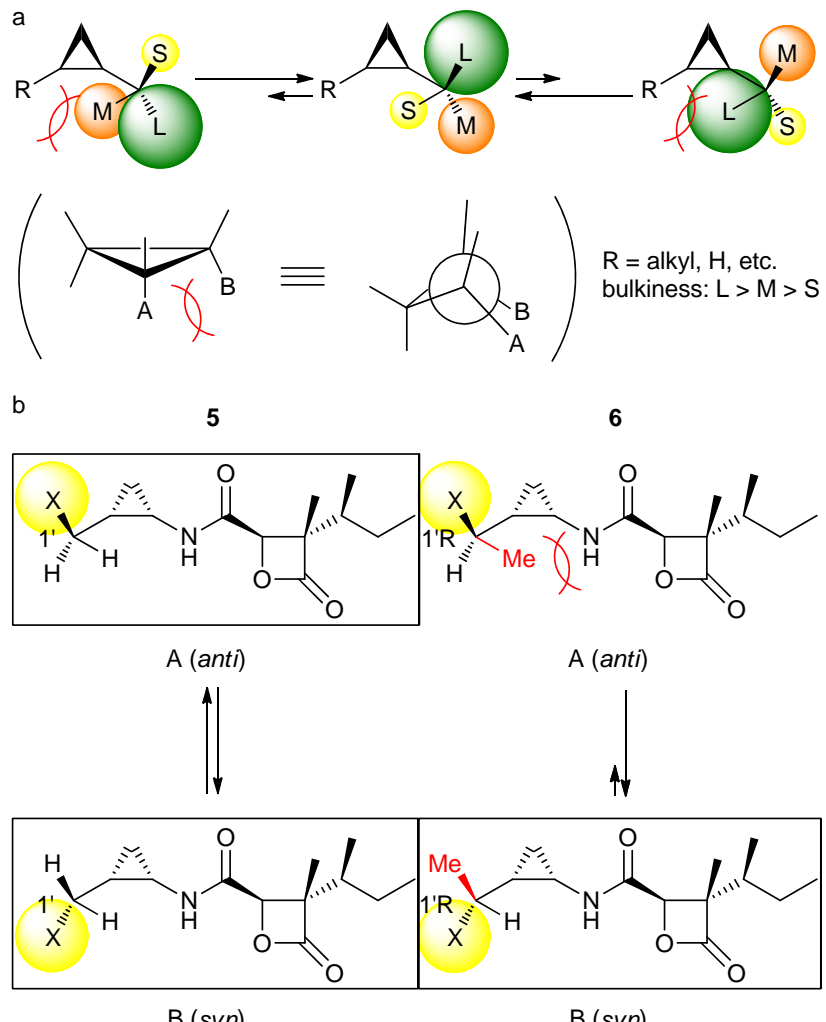

Figure 5. The cyclopropylic strain-based conformational restriction. (a) General representation of the cyclopropylic strain. (b) Presumed stable conformation of 5 (syn/anti) and 6 (syn).

Synthesis. The target compounds 3a-6a would be obtained by condensation between the unit $\mathbf{A}$ or $\mathbf{B}$ and the unit $\mathbf{C}, \mathbf{D}$, or $\mathbf{E}$. Although the synthesis of units $\mathbf{A}$ and $\mathbf{B}$ was described in our previous report, ${ }^{14 b, 20}$ we needed to prepare the $\beta$-lactone units $\mathbf{C}$-E (Scheme 1). In particular, in the synthesis of $\mathbf{D}$ and $\mathbf{E}$, construction of the chiral all-carbon quaternary center adjacent to the $\beta$-lactone carbonyl group would be a key step.

Scheme 1. Synthetic plan of 3a-6a

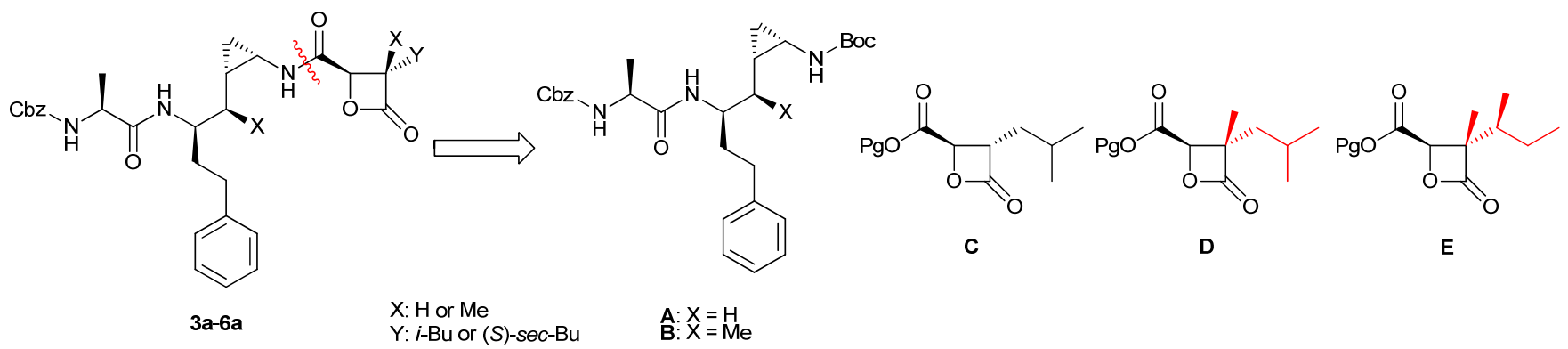

The $\beta$-lactone unit $\mathbf{C}$ was prepared as shown in Scheme 2, using a procedure similar to that for the preparation of the $\beta$-lactone unit in the total synthesis of belactosin A by Armstrong et al. ${ }^{21}$ 4-Methylpentanoic acid 7 was condensed with (4R)-4-benzyl-2-oxazolidinone by the mixed anhydride method using $\mathrm{LiCl}$ as an additive ${ }^{22}$ to give $\mathbf{8}$, which was treated 
with $\mathrm{BrCH}_{2} \mathrm{CO}_{2} t$-Bu/NaHMDS at $-78{ }^{\circ} \mathrm{C}$ in THF to afford $\mathbf{9}$ stereoselectively. ${ }^{23,24}$ The oxazolidinone moiety of 9 was removed by hydrolysis with $\mathrm{LiOH} / \mathrm{H}_{2} \mathrm{O}_{2}$ in aqueous THF to give $\mathbf{1 0} .^{25}$ The $\alpha$-position of the $t$-butyl ester in $\mathbf{1 0}$ was diastereoselectively chlorinated with $\mathrm{CCl}_{4} / \mathrm{LiHMDS}$ in THF at $-78{ }^{\circ} \mathrm{C},{ }^{26}$ which seemed to proceed through the Li-chelated seven-membered dianion transition state, ${ }^{23 \mathrm{~b}}$ followed by the ring-closing reaction under alkaline two-phase conditions to afford the $\beta$-lactone $\mathbf{1 1}$ (unit $\mathbf{C}, \mathrm{Pg}=t$-Bu). ${ }^{27}$

Scheme 2. Synthesis of $\beta$-lactone units $\mathbf{C}$ and $\mathrm{D}$

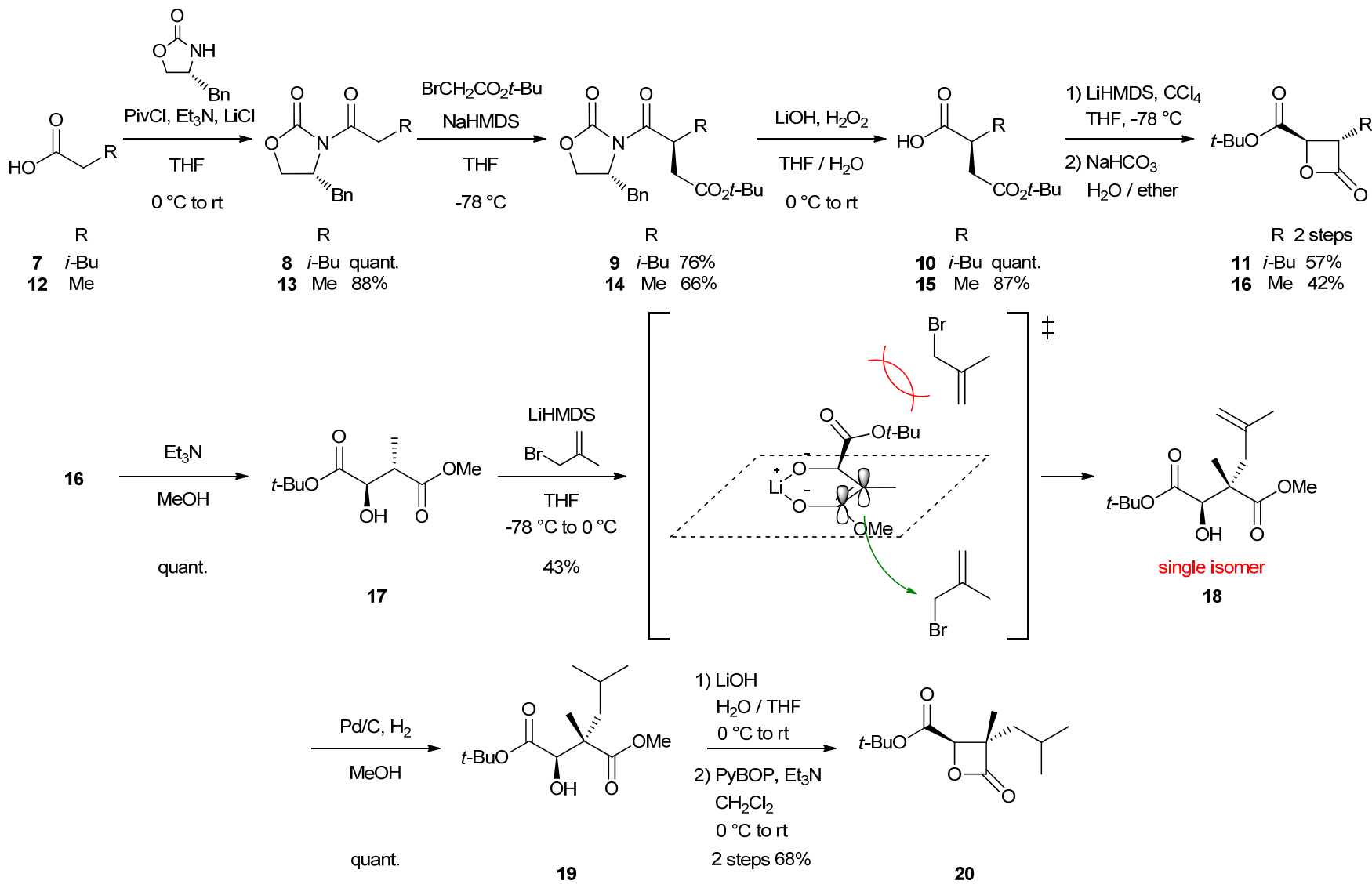

The synthesis of the unit $\mathbf{D}$ is also shown in Scheme 2. Starting from propionic acid 12, the $\beta$-lactone $\mathbf{1 6}$ was prepared according to the same procedure used for the synthesis of $\mathbf{1 1}$. Methanolysis of $\mathbf{1 6}$ yielded the ring-opened product 17, the substrate for the key reaction forming the asymmetric quaternary carbon center. Treatment of $\mathbf{1 7}$ with LiHMDS/3-bromo-2-methylpropene in THF at $-78{ }^{\circ} \mathrm{C}$ to $0{ }^{\circ} \mathrm{C}$ afforded the desired alkylated product 18 as a single isomer. ${ }^{28}$ The reaction seemed to proceed through the Li-chelated six-membered transition state, in which the bulky $t$-butyl ester group prevents access of the electrophile from the upper side as shown in Scheme $2 .{ }^{29}$ Hydrogenation of 18 afforded 19, and subsequently its methyl ester moiety was selectively hydrolyzed with $\mathrm{LiOH}$ in aqueous THF, followed by ring-closing reaction with $\mathrm{PyBOP}^{30}$ to afford the $\beta$-lactone $\mathbf{2 0}$ (unit $\mathrm{D}, \mathrm{Pg}=t$-Bu). The relative stereochemistry of 20 was determined by NOE experiments (Figure 6-a). ${ }^{31}$

The synthesis of the unit $\mathbf{E}$ is shown in Scheme 3. L-Isoleucine (21) was deaminated ${ }^{32}$ to afford 22, which was converted to the alcohol $\mathbf{2 5}$ according to the same procedure used for the synthesis of $\mathbf{1 7}$ described above. Next, we tried to construct the asymmetric quaternary carbon center by stereoselective methylation of $\mathbf{2 5}$ as in the synthesis of the unit $\mathbf{D}$. Although the reaction was investigated under various conditions, it did not proceed at all. Because the bulky 
(S)-sec-butyl side chain of 25 seems to lower the reactivity, we next examined the methylation reaction with the $\beta$-lactone ${ }^{33} \mathbf{2 7}$ as a substrate, which was prepared by removal of the $t$-butyl group of $\mathbf{2 4}$ with TFA. Thus, when $\mathbf{2 7}$ was treated with LDA/MeI in THF at $-78{ }^{\circ} \mathrm{C}$, the desired methylated product $\mathbf{2 8}$ was obtained as a diastereomeric mixture (dr 3:1), while the yield was low. The stereoselectivity of the reaction might be caused by steric repulsion due to the carboxy group as depicted in Scheme 3. The carboxy group of $\mathbf{2 8}$ was re-protected with a $t$-butyl group and subsequent methanolysis gave 26, which was obtained as a single isomer after silica gel column chromatography purification. The secondary alcohol moiety of $\mathbf{2 6}$ was oxidized with Dess-Martin periodinane and subsequent reduction of the resulting carbonyl group with $(R)$-2-methyl-CBS-1,3,2-oxazaborolidine ${ }^{34}$ resulted in complete inversion of its stereochemistry to give the corresponding epimer 29. Although we attempted to selectively hydrolyze the methyl ester moiety of $\mathbf{2 9}$, the desired mono-ester 30 was not obtained at all, even under $\mathrm{S}_{\mathrm{N}} 2$ reaction conditions. Thus, we hydrolyzed both the methyl and t-butyl ester moieties of $\mathbf{2 9}$, and then the product was successively treated with TFAA and with benzyl alcohol, which gave the desired benzyl ester $\mathbf{3 1}$ exclusively. ${ }^{35}$ Finally, $\mathbf{3 1}$ was treated with $\mathrm{PyBOP}^{30}$ to yield the $\beta$-lactone 32 (unit $\mathbf{E}, \mathrm{Pg}=\mathrm{Bn}$ ). The relative stereochemistry of $\mathbf{3 2}$ was determined by NOE experiments (Figure 6-b). ${ }^{36}$ 
Scheme 3. Synthesis of $\beta$-lactone unit $\mathbf{E}$
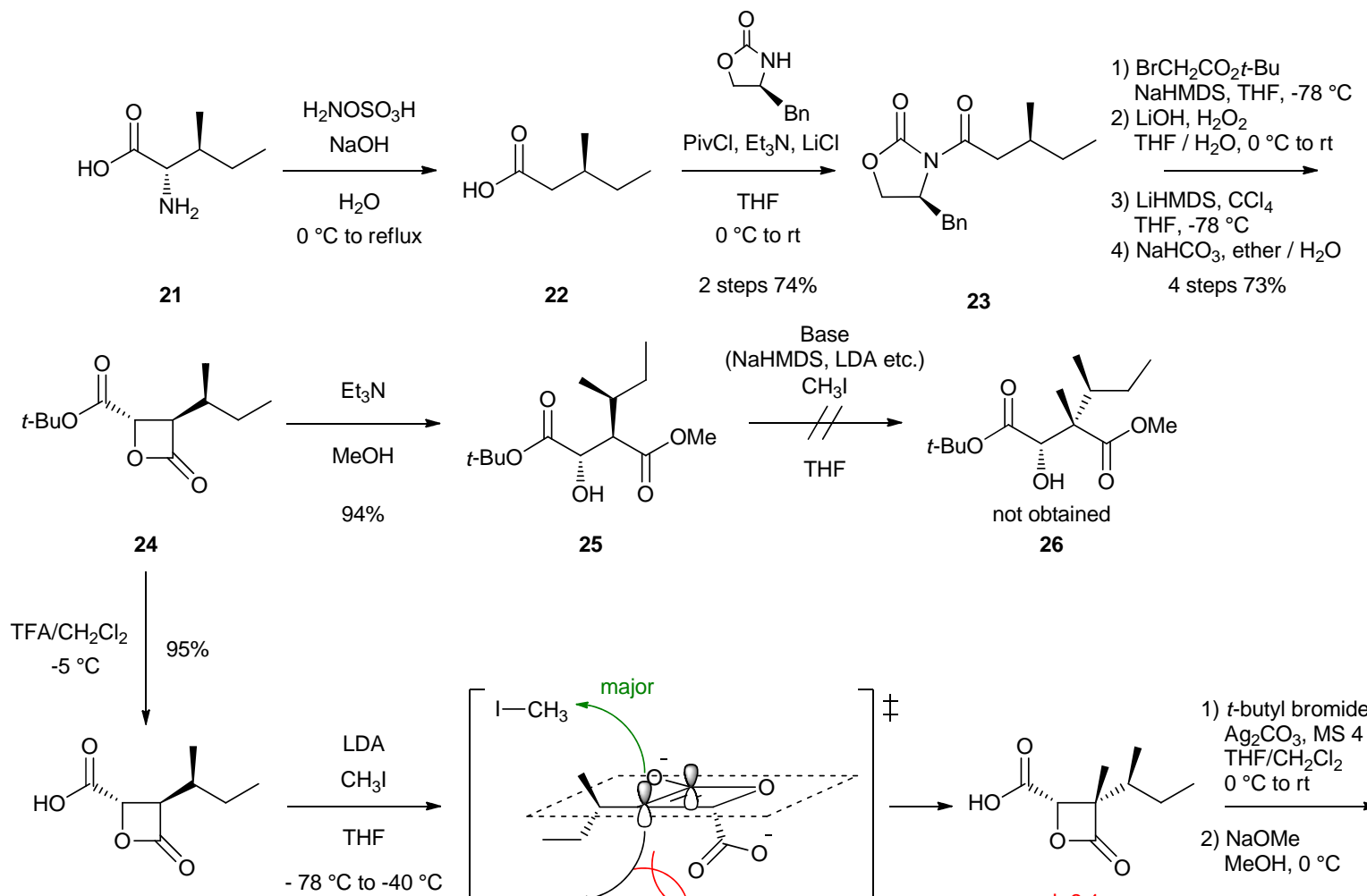

25

26

27<smiles>CCC(C)[C@H](C)[C@H](O)C(=O)OC(C)(C)C</smiles>

single isomer

26

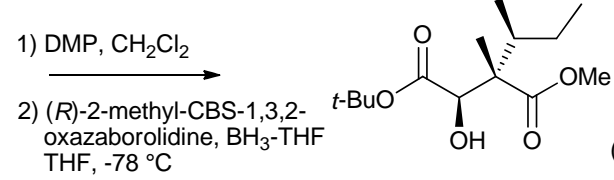

2 steps $98 \%$
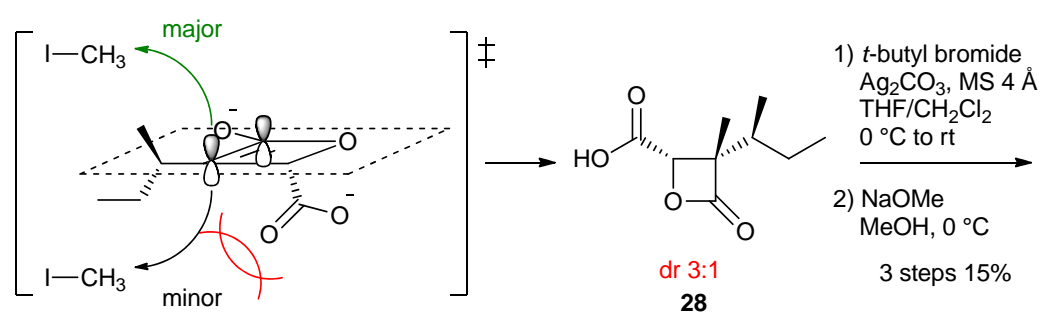

hydrolytic conditions ( $\mathrm{LiOH}, \mathrm{NaOH})$

SN2 conditions (Lil, TMSOK, RSNa, RSLi)<smiles>CC[C@H](C)[C@@](C)(C(=O)O)[C@@H](O)C(=O)OC(C)(C)C</smiles>

not obtained 1) $\mathrm{NaOH}$, dioxane $/ \mathrm{H}_{2} \mathrm{O}$
$80^{\circ} \mathrm{C}$
2) $\mathrm{TFAA}, 0^{\circ} \mathrm{C}$
3) $\mathrm{BnOH}$

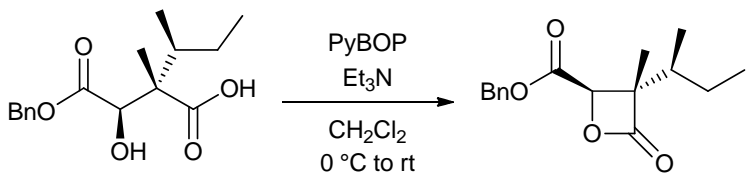

31 $75 \%$ 


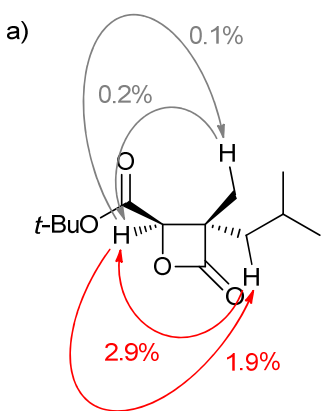

20

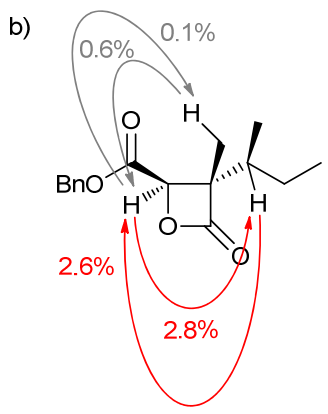

32

Figure 6. NOE experiments of $\mathbf{2 0}$ (a) and $\mathbf{3 2}$ (b)

The synthesized $\beta$-lactone units 11, 20 and 32 were deprotected and finally condensed with unit $\mathbf{A}$ or $\mathbf{B}$ to yield 3a-6a. Compounds 3b-6b were also synthesized by hydrogenolysis of 3a-6a (Scheme 4).

Scheme 4. Synthesis of 3a-6a and $3 \mathbf{b}-\mathbf{6}-\mathbf{b}^{a}$<smiles>CC(C)C1C(=O)OC1C(=O)O[Mg]</smiles>

11: $\mathrm{R}=\mathrm{H}$ 20: $R=M e$<smiles>[R]C(C)C1C(=O)OC1C(=O)O</smiles>
33: $\mathrm{R}=\mathrm{H}$ 34: $\mathrm{R}=\mathrm{Me}$

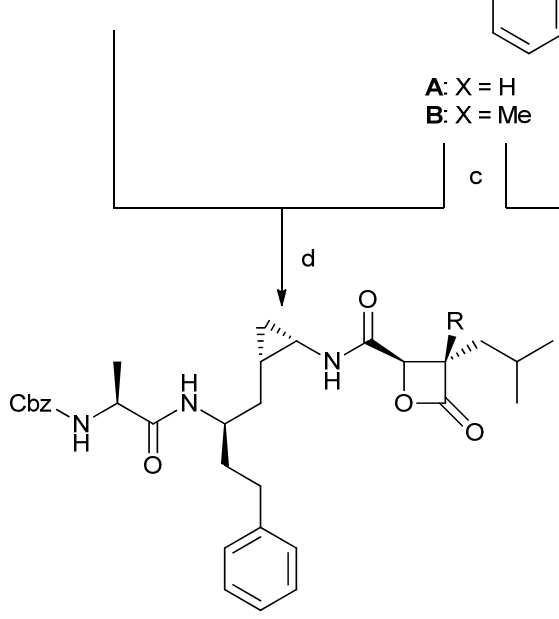

3a: $\mathrm{R}=\mathrm{H}$

4a: $\mathrm{R}=\mathrm{Me}$

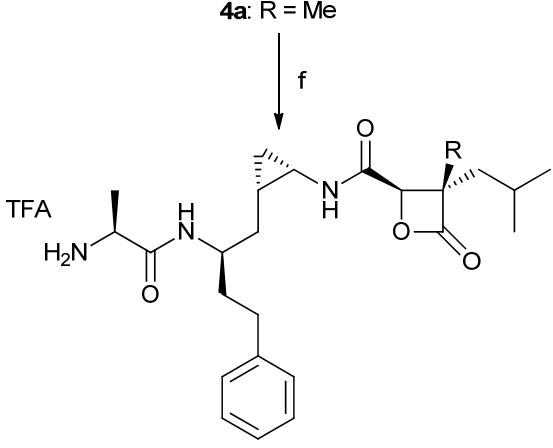

3b: $\mathrm{R}=\mathrm{H}$ 4b: $\mathrm{R}=\mathrm{Me}$

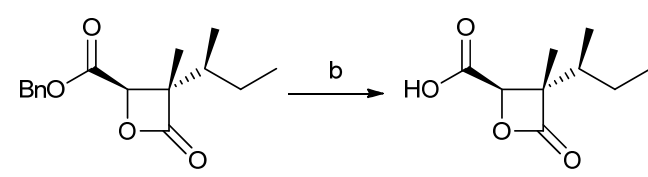

32

35

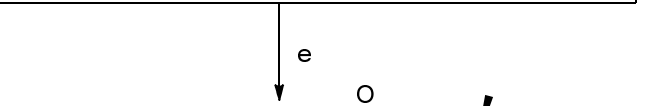

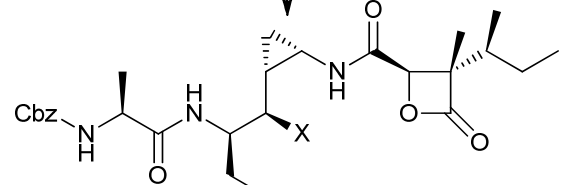

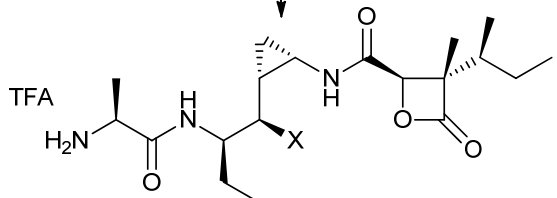<smiles></smiles>

${ }^{a}$ Reagents and conditions: (a) TFA $/ \mathrm{CH}_{2} \mathrm{Cl}_{2},-5^{\circ} \mathrm{C}$; (b) Pd/C, $\mathrm{H}_{2}$, THF, quant.; (c) TFA $/ \mathrm{CH}_{2} \mathrm{Cl}_{2}$; (d) $\mathrm{PivCl}, \mathrm{Et}_{3} \mathrm{~N}, \mathrm{CH}_{2} \mathrm{Cl}_{2}$, $0{ }^{\circ} \mathrm{C}$ to rt, $62 \%$ (3a, 2 steps from A), $100 \%$ (4a, 2 steps from A); (e) $\mathrm{EDC} \cdot \mathrm{HCl}, \mathrm{HOAt}, \mathrm{Et}_{3} \mathrm{~N}, \mathrm{CH}_{2} \mathrm{Cl}_{2}, 0{ }^{\circ} \mathrm{C}$, quant. (5a, 2 steps from A), 91\% (6a, 2 steps from B); (f) Pd/C, $\mathrm{H}_{2}$, TFA/THF, $0{ }^{\circ} \mathrm{C}$, quant. (3b-6b) 


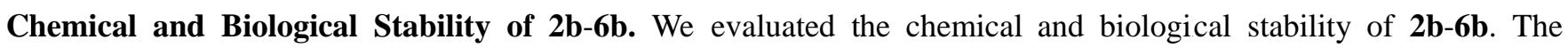
compounds were incubated in 0.1 M TEAA buffer ( $\mathrm{pH}$ 7.4) or human $\mathrm{AB}$ serum at $37^{\circ} \mathrm{C}$, and the time courses were analyzed by HPLC to obtain the half-life $\left(\mathrm{t}_{1 / 2}\right)$, the results of which are shown in Figure 6. In 0.1 M TEAA buffer, the order of their stability was $\mathbf{3 b}<\mathbf{2 b}<\mathbf{4 b} \mathbf{b} \mathbf{5} \mathbf{b}, \mathbf{6} \mathbf{b}$, which clearly corresponds to the order of the steric hindrance around their $\beta$-lactone carbonyl group (Figure $4-a$ ), as we expected. Notably, $\mathbf{4 b}, \mathbf{5 b}$, and $\mathbf{6 b}$ which have a quaternary carbon adjacent to their $\beta$-lactone carbonyl group were quite stable and no degradation was observed under the conditions.

Similarly, in human AB serum, the order of their stability was $\mathbf{3 b}<\mathbf{2 b}<\mathbf{4 b}<\mathbf{5 b}<\mathbf{6 b}$, where the relative stability of $\mathbf{2 b}$-5b also depended on the steric hindrance around their $\beta$-lactone carbonyl group, while their half-life was remarkably short compared with those in 0.1 M TEAA buffer, suggesting that $\mathbf{2 b} \mathbf{b}-\mathbf{6} \mathbf{b}$ were degraded enzymatically in human $\mathrm{AB}$ serum. Furthermore, $\mathbf{6} \mathbf{b}$, the conformationally restricted analog of $\mathbf{5 b}$, was significantly more stable than $\mathbf{5 b}$, of which the $t_{1 / 2}$ was longer than $1 \mathrm{~h}$. Therefore, the conformational restriction might result in lowering affinity for the degradation enzyme, as we hypothesized. This finding is an interesting example of the correlation between conformational flexibility and biological instability. Thus, we successfully identified $\mathbf{6 a}$ as a chemically and biologically stable analog of $\mathbf{2 a}$.
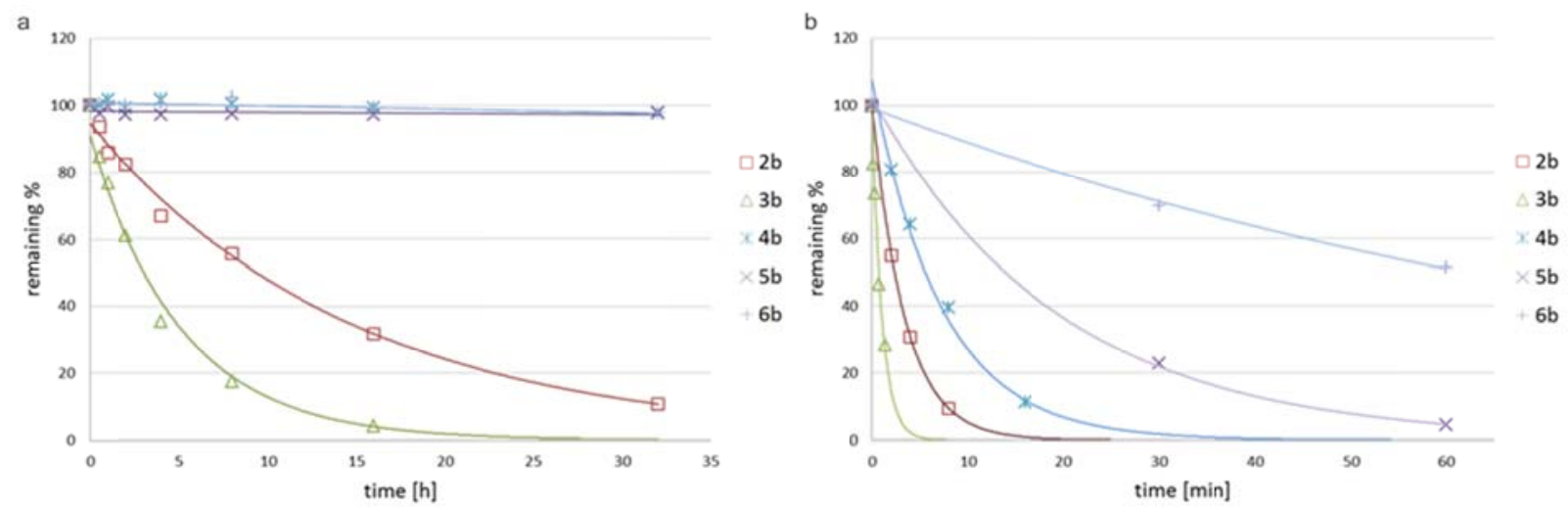

C

\begin{tabular}{ccc}
\hline \multirow{2}{*}{ compound } & \multicolumn{2}{c}{$\mathrm{t}_{1 / 2}$ at $37^{\circ} \mathrm{C}$} \\
\cline { 2 - 3 } & 0.1 M TEAA buffer $(\mathrm{pH} \mathrm{7.4)}[\mathrm{h}]$ & human AB serum [min] \\
\hline \hline $\mathbf{2 b}$ & 10 & 2.3 \\
$\mathbf{3 b}$ & 3.5 & 0.73 \\
$\mathbf{4 b}$ & $\mathrm{ND}$ & 5.0 \\
$\mathbf{5 b}$ & $\mathrm{ND}$ & 14 \\
$\mathbf{6 b}$ & $\mathrm{ND}$ & 63 \\
\hline
\end{tabular}

Figure 7. Chemical and biological stability of $\mathbf{2 b - 6 b}$. (a) Time courses of $\mathbf{2 b - 6 b}$ in $0.1 \mathrm{M}$ TEAA buffer (pH 7.4) at 37

${ }^{\circ} \mathrm{C}$ analyzed by HPLC. (b) Time courses of $\mathbf{2 b} \mathbf{b}-\mathbf{6 b}$ in human AB serum at $37^{\circ} \mathrm{C}$ analyzedl by HPLC. (c) Calculated half-life of $\mathbf{2 b - 6 b}$ in each conditions. ND: not degraded

Pharmacological Effects of 6a. We investigated the inhibitory effect of the highly stable $\mathbf{6 a}$ on the CT-L activity of proteasome and HCT116 cell growth (Table 2). Notably, 6a $\left(\mathrm{IC}_{50}=4.0 \mu \mathrm{M}\right)$ showed a cell growth inhibitory effect 
comparable to that of $\mathbf{2 a}\left(\mathrm{IC}_{50}=1.8 \mu \mathrm{M}\right)$, despite its significantly lowered proteasome inhibitory activity $\left(\mathrm{IC}_{50}=1.3\right.$ $\mu \mathrm{M})$ compared with that of $\mathbf{2 a}\left(\mathrm{IC}_{50}=0.0057 \mu \mathrm{M}\right)$. The $\mathrm{IC}_{50}$ ratio (cell growth/CT-L activity) of $\mathbf{6 a}$ was 3.1, which is remarkably improved over that of $\mathbf{2 a}$ (319), and it was almost the same as those of bortezomib and carfilzomib (Table 1). These findings suggest that the lower cell growth inhibitory effect of 2a arises from its instability as we expected, and that structural optimization of $\mathbf{6 a}$ might lead to development of highly potent cell growth inhibitors.

Table 2. Inhibitory Effect of 6a on Proteasome CT-L Activity and HCT116 Cell Growth

\begin{tabular}{cccc}
\hline \multirow{2}{*}{ compound } & \multicolumn{2}{c}{$\mathrm{IC}_{50}[\mu \mathrm{M}]$} & \multicolumn{2}{c}{$\begin{array}{c}\mathrm{IC}_{50} \text { ratio } \\
\text { (cell growth/CT-L activity) }\end{array}$} \\
\cline { 2 - 3 } & CT-L activity (proteasome) & cell growth (HCT116) & (c) \\
\hline \hline 2a & 0.0057 & 1.8 & 319 \\
$\mathbf{6 a}$ & 1.3 & 4.0 & 3.1 \\
\hline
\end{tabular}

${ }^{a}$ Based on three experiments.

In summary, by chemical modification of $\mathbf{2 a}$, we successfully developed a chemically and biologically stabilized analog $\mathbf{6 a}$, in which the steric hindrance around the unstable $\beta$-lactone moiety and the cyclopropylic strain-based conformational restriction would work together to stabilize the molecule. The cell growth inhibitory activity of $\mathbf{6 a}$ is comparable to its proteasome inhibitory activity, so that the structural optimization of $\mathbf{6 a}$ might result in highly potent cell growth inhibitors. The chemical and biological stability of 2a derivatives are well correlated to the steric hindrance around their $\beta$-lactone carbonyl group due to the bulkiness of their $\alpha$-carbon substituents. Furthermore, conformational restriction by the cyclopropylic strain resulted in significant stabilization in human serum probably due to the decreased affinity for metabolic enzymes. The correlation between conformation and metabolic stability is not studied well, and this study presented an interesting example of their clear correlation.

\section{Abbreviations Used}

Bn, benzyl; Boc, t-butoxycarbonyl; CBS, Corey-Bakshi-Shibata; Cbz, benzyloxycarbonyl; CT-L, chymotrypsin-like; DMP, Dess-Martin periodinane; EDC, 1-Ethyl-3-(3-dimethylaminopropyl)carbodiimide; Et, ethyl; HOAt, 1-Hydroxy-7-azabenzotriazole; HPLC, high-pressure liquid chromatography; LDA, lithium diisopropylamide; LiHMDS, lithium hexamethyldisilazide; Me, methyl; Piv, pivaloyl; PyBOP, benzotriazol-1-yl-oxytripyrrolidinophosphonium hexafluorophosphate; NaHMDS, sodium hexamethyldisilazide; NOE, nuclear Overhauser effect; SAR, structure activity relationship; TEAA, triethylammonium acetate; TFA, trifluoroacetic acid; TFAA , trifluoroacetic anhydride; THF, tetrahydrofuran; Thr, threonine; TMS, trimethylsilyl; UPR, unfolded protein response

\section{References}

1. (a) A. E. Nassar, A. M. Kamel and C. Clarimont, Drug Discovery Today, 2004, 9, 1020-1028; (b) T. N. Thompson, Med. Res. Rev., 2001, 21, 412-449.

2. (a) A. F. Stepan, D. P. Walker, J. Bauman, D. A. Price, T. A. Baillie, A. S. Kalgutkar and M. D. Aleo, Chem. Res. Toxicol., 2011, 24, 1345-1410; (b) Y. Z. Shu, B. M. Johnson and T. J. Yang, The AAPS journal, 2008, 10, 178-192; 
(c) D. C. Evans, A. P. Watt, D. A. Nicoll-Griffith and T. A. Baillie, Chem. Res. Toxicol., 2003, 17, 3-16; (d) D. K. Dalvie, A. S. Kalgutkar, S. C. Khojasteh-Bakht, R. S. Obach and J. P. O'Donnell, Chem. Res. Toxicol., 2002, 15, 269-299.

3. (a) M. Orlowski, Biochemistry, 1990, 29, 10289-10297; (b) A. Ciechanover, Cell, 1994, 79, $13-21$.

4. (a) S. Y. Fuchs, Cancer Biol. Ther., 2002, 1, 337-341; (b) J. J. Chen, F. Lin and Z. H. Qin, Neurosci. Bull., 2008, 24, 183-194.

5. $\quad$ R. W. King, R. J. Deshaies, J. M. Peters and M. W. Kirschner, Science, 1996, 274, 1652-1659.

6. (a) D. Ron and P. Walter, Nat. Rev. Mol. Cell Biol., 2007, 8, 519-529; (b) S. S. Vembar and J. L. Brodsky, Nat. Rev. Mol. Cell Biol., 2008, 9, 944-957; (c) M. M. Hiller, A. Finger, M. Schweiger and D. H. Wolf, Science, 1996, 273, 1725-1728.

7. (a) J. Adams, Nat. Rev. Cancer, 2004, 4, 349-360; (b) A. F. Kisselev, W. A. van der Linden and H. S. Overkleeft, Chem. Biol., 2012, 19, 99-115; (c) L. R. Dick and P. E. Fleming, Drug Discovery Today, 2010, 15, 243-249; (d) R. Z. Orlowski and D. J. Kuhn, Clin. Cancer Res., 2008, 14, 1649-1657.

8. (a) P. F. Bross, R. Kane, A. T. Farrell, S. Abraham, K. Benson, M. E. Brower, S. Bradley, J. V. Gobburu, A. Goheer, S. L. Lee, J. Leighton, C. Y. Liang, R. T. Lostritto, W. D. McGuinn, D. E. Morse, A. Rahman, L. A. Rosario, S. L. Verbois, G. Williams, Y. C. Wang and R. Pazdur, Clin. Cancer Res., 2004, 10, 3954-3964; (b) R. C. Kane, A. T. Farrell, R. Sridhara and R. Pazdur, Clin. Cancer Res., 2006, 12, 2955-2960.

9. $\quad$ R. C. Kane, R. Dagher, A. Farrell, C. W. Ko, R. Sridhara, R. Justice and R. Pazdur, Clin. Cancer Res., 2007, 13, 5291-5294.

10. (a) A. Asai, A. Hasegawa, K. Ochiai, Y. Yamashita and T. Mizukami, J. Antibiot., 2000, 53, 81-83; (b) A. Asai, T. Tsujita, S. V. Sharma, Y. Yamashita, S. Akinaga, M. Funakoshi, H. Kobayashi and T. Mizukami, Biochem. Pharmacol., 2004, 67, 227-234.

11. M. Groll, O. V. Larionov, R. Huber and A. De Meijere, Proc. Natl. Acad. Sci. U. S. A., 2006, 103, 4576-4579.

12. (a) L. Borissenko and M. Groll, Chem. Rev., 2007, 107, 687-717; (b) V. S. Korotkov, A. Ludwig, O. V. Larionov, A. V. Lygin, M. Groll and A. de Meijere, Org. Biomol. Chem., 2011, 9, 7791-7798.

13. K. Yoshida, K. Yamaguchi, T. Sone, Y. Unno, A. Asai, H. Yokosawa, A. Matsuda, M. Arisawa and S. Shuto, Org. Lett., 2008, 10, 3571-3574.

14. (a) K. Yoshida, K. Yamaguchi, A. Mizuno, Y. Unno, A. Asai, T. Sone, H. Yokosawa, A. Matsuda, M. Arisawa and S. Shuto, Org. Biomol. Chem., 2009, 7, 1868-1877; (b) S. Kawamura, Y. Unno, A. List, A. Mizuno, M. Tanaka, T. Sasaki, M. Arisawa, A. Asai, M. Groll and S. Shuto, J. Med. Chem., 2013, 56, 3689-3700.

15. J. Adams, M. Behnke, S. Chen, A. A. Cruickshank, L. R. Dick, L. Grenier, J. M. Klunder, Y. T. Ma, L. Plamondon and R. L. Stein, Bioorg. Med. Chem. Lett., 1998, 8, 333-338.

16. D. J. Kuhn, Q. Chen, P. M. Voorhees, J. S. Strader, K. D. Shenk, C. M. Sun, S. D. Demo, M. K. Bennett, F. W. van Leeuwen, A. A. Chanan-Khan and R. Z. Orlowski, Blood, 2007, 110, 3281-3290.

17. M. J. Williamson, J. L. Blank, F. J. Bruzzese, Y. Cao, J. S. Daniels, L. R. Dick, J. Labutti, A. M. Mazzola, A. D. Patil, C. L. Reimer, M. S. Solomon, M. Stirling, Y. Tian, C. A. Tsu, G. S. Weatherhead, J. X. Zhang and M. Rolfe, Mol. Cancer Ther., 2006, 5, 3052-3061.

18. M. S. Newman, Steric effects in organic chemistry, J. Wiley, 1956.

19. (a) S. Shuto, S. Ono, Y. Hase, N. Kamiyama, H. Takada, K. Yamasihita and A. Matsuda, J. Org. Chem., 1996, 61, 915-923; (b) S. Shuto, S. Ono, Y. Hase, Y. Ueno, T. Noguchi, K. Yoshii and A. Matsuda, J. Med. Chem., 1996, 39, 
4844-4852; (c) S. Shuto, S. Ono, H. Imoto, K. Yoshii and A. Matsuda, J. Med. Chem., 1998, 41, 3507-3514; (d) S. Ono, K. Ogawa, K. Yamashita, T. Yamamoto, Y. Kazuta, A. Matsuda and S. Shuto, Chem. Pharm. Bull., 2002, 50, 966-968; (e) K. Yamaguchi, Y. Kazuta, K. Hirano, S. Yamada, A. Matsuda and S. Shuto, Bioorg. Med. Chem., 2008, 16, 8875-8881; (f) M. Watanabe, T. Hirokawa, T. Kobayashi, A. Yoshida, Y. Ito, S. Yamada, N. Orimoto, Y. Yamasaki, M. Arisawa and S. Shuto, J. Med. Chem., 2010, 53, 3585-3593.

20. S. Kawamura, Y. Unno, M. Tanaka, T. Sasaki, A. Yamano, T. Hirokawa, T. Kameda, A. Asai, M. Arisawa and S. Shuto, J. Med. Chem., 2013, 56, 5829-5842.

21. A. Armstrong and J. N. Scutt, Chem. Commun., 2004, 510-511.

22. G.-J. Ho and D. J. Mathre, J. Org. Chem., 1995, 60, 2271-2273.

23. (a) D. A. Evans, L. D. Wu, J. J. M. Wiener, J. S. Johnson, D. H. B. Ripin and J. S. Tedrow, J. Org. Chem., 1999, 64, 6411-6417; (b) R. P. Beckett, M. J. Crimmin, M. H. Davis and Z. Spavold, Synlett, 1993, 137-138.

24. In the reaction, undesired diastereomer was not observed in the crude ${ }^{1} \mathrm{H}-\mathrm{NMR}$

25. D. A. Evans, T. C. Britton and J. A. Ellman, Tetrahedron Lett., 1987, 28, 6141-6144.

26. B. Barlaam, T. G. Bird, C. Lambert-van der Brempt, D. Campbell, S. J. Foster and R. Maciewicz, J. Med. Chem., 1999, 42, 4890-4908.

27. In the reaction, undesired diastereomer was not observed in the crude ${ }^{1} \mathrm{H}-\mathrm{NMR}$

28. In this reaction, significant amount of trimethylsilylated product of $\mathbf{1 8}$ was obtained.

29. G. Frater, U. Mueller and W. Guenther, Tetrahedron, 1984, 40, 1269-1277.

30. N. Valls, M. Borregán and J. Bonjoch, Tetrahedron Lett., 2006, 47, 3701-3705.

31. Absolute stereochemistry of $\mathbf{2 0}$ was determined based on the known specific optical rotation of compound $\mathbf{1 5}$.

32. G. A. Doldouras and J. Kollonitsch, J. Am. Chem. Soc., 1978, 100, 341-342.

33. J. Mulzer and T. Kerkmann, J. Am. Chem. Soc., 1980, 102, 3620-3622.

34. E. J. Corey and C. J. Helal, Angew. Chem. Int. Ed., 1998, 37, 1986-2012.

35. (a) B. Rajashekhar and E. T. Kaiser, J. Org. Chem., 1985, 50, 5480-5484; (b) G. P. Liesen and C. N. Sukenik, J. Org. Chem., 1987, 52, 455-457.

36. The synthesis of the $(2 R, 3 S)$-diastereomer of $\mathbf{2 4}$ was reported previously by Armstrong et al. using $(R)$-oxazolidinone instead of (S)-oxazolidinone (ref. 21). The $[\alpha]_{\mathrm{D}}$ and NMR data of 24 are different from those of the reported diastereomer. Thus, absolute configuration of $\mathbf{3 2}$ was determined as shown in Scheme 3. 